\title{
C-Reactive Protein Alone or Combined With Cardiac Troponin T for Risk Stratification of Respiratory Intensive Care Unit Patients
}

\author{
Savas Ozsu MD, Gurdal Yilmaz MD, Ismail Yilmaz MD, Funda Oztuna MD, \\ Yilmaz Bulbul MD, and Tevfik Ozlu MD
}

\begin{abstract}
BACKGROUND: Mortality is high among patients admitted to intensive care units (ICUs). Several prognostic markers have been described in such patients, but the literature contains no data comparing C-reactive protein (CRP) and cardiac troponin $\mathrm{T}$ (cTn-T), nor of a combination of CRP and cTn-T in the same patient group in the ICU. METHODS: This was a retrospective electronic data review of patients who presented to the emergency department for respiratory reasons between December 2007 and December 2009 and in whom CRP and cTn-T levels were measured. Patients with a diagnosis of pulmonary embolism and acute coronary syndrome were excluded. We recorded demographics, chronic diseases, admission diagnosis, Simplified Acute Physiology Score II (SAPS II), ICU stay, and CRP and cTn-T concentrations. RESULTS: We included the records of 158 patients. Mean ICU stay was 9.9 days (range 1-65 d), and mean hospital stay was $\mathbf{1 4 . 1}$ days (range 1-72 d). For predicting mortality, receiver operating characteristic analysis gave a CRP cutoff value of $\geq 10 \mathrm{mg} / \mathrm{dL}$, and a CTn-T cutoff value of $\geq 0.01 \mathrm{ng} / \mathrm{mL}$. For CRP the mortality area under the curve was 0.691 (95\% CI $0.608-0.775)$, the sensitivity was $65 \%$, and the specificity was $70 \%$. For cTn-T the mortality area under the curve was 0.733 (95\% CI $0.655-0.812)$, the sensitivity was $78 \%$, and the specificity was $56 \%$. Of the patients who died, $65 \%$ had CRP $\geq 10 \mathrm{mg} / \mathrm{dL}$ and $78 \%$ had cTn-T $\geq 0.01 \mathrm{ng} / \mathrm{mL}$. On multivariable regression analysis, CRP $\geq 10 \mathrm{mg} / \mathrm{dL}$ was associated with 6.6-fold higher (95\% CI 1.7-21.3) ICU mortality. There was no advantage for models that combined CRP and cTn-T. CRP alone was more valuable in predicting ICU mortality than in combination with troponin or SAPS II. CONCLUSIONS: Elevated CRP is an independent early prognostic marker of mortality risk in ICU patients. We suspect that a CRP-based prognosis strategy may be useful. Key words: C-reactive protein; troponin; respiratory disease; prognosis; mortality. [Respir Care 2011;56(7):1002-1008. (C) 2011 Daedalus Enterprises]
\end{abstract}

\section{Introduction}

Cardiac troponins, which include cardiac troponin I (cTn-I) and cardiac troponin $\mathrm{T}(\mathrm{cTn}-\mathrm{T})$, are highly sensi-

Savas Ozsu MD, Ismail Yilmaz MD, Funda Oztuna MD, Yilmaz Bulbul MD, and Tevfik Ozlu MD are affiliated Department of Chest Diseases; and Gurdal Yilmaz MD is affiliated with the Department of Infectious Diseases and Clinical Microbiology, Karadeniz Technical University School of Medicine, Trabzon, Turkey.

The authors have disclosed no conflicts of interest.

Correspondence: Savas Ozsu MD, Department of Chest Diseases, Karadeniz Teknik Üniversitesi Tıp Fakültesi, Gögüus Hastalıkları AD, Trabzon 61080 Turkey. E-mail: savasozsu@gmail.com.

DOI: $10.4187 /$ respcare.01007 tive and specific biochemical markers of myocardial injury. Elevated cTn-T helps diagnose acute coronary syndrome, whereas serially negative troponins reliably exclude acute coronary syndrome..$^{1-3}$ Elevated cardiac troponins also occur in patients with non-ischemic myocardial injury, who have congestive heart failure, myocarditis, sepsis, or trauma, and in patients with chronic renal insufficiency. ${ }^{4}$ Elevated troponin also correlates with mortality and morbidity in intensive care unit (ICU) patients. ${ }^{5-7}$ The troponin level in these patients is thought to increase secondary to myocardial damage from underlying disease, hypoxia, acidosis, and/or therapies. ${ }^{8}$

C-reactive protein (CRP) is secreted by the liver, and plasma CRP rapidly rises in response to inflammation, so it is an important biomarker of systemic inflammation. ${ }^{9}$ CRP correlates with long-term mortality and morbidity in 
patients with COPD, rheumatoid disease, coronary artery disease, and chronic inflammation. ${ }^{10,11}$ Response to antiinflammatory treatment can be monitored with CRP. ${ }^{12} \mathrm{Al}-$ though the underlying primary disease determines mortality and morbidity in ICU patients, the degree of acute systemic inflammation correlates with ICU and hospital mortality. ${ }^{13}$

Most inflammatory and cardiac biomarkers have been investigated individually, but the use of a single biomarker may not adequately represent the severity of disease process. The use of troponin $\mathrm{T}$ and N-terminal pro-brain natriuretic peptide (NT-proBNP) in pulmonary embolism, and positive CRP and fibrinogen in cardiovascular diseases predicted overall mortality better than their individual use. ${ }^{14,15} \mathrm{Wu}$ et al found that the combination of Tn-I and high Acute Physiology and Chronic Health Evaluation (APACHE II) score was a better risk stratification predictor in ICU patients than was high APACHE II score or elevated Tn-I alone. ${ }^{7}$ Therefore, accumulating evidence appears to support the strategy of using multiple biomarkers and assessment instruments in prognosis.

To our knowledge, no previous studies have investigated the combination of CRP and other biomarkers in the ICU patients. We investigated CRP, Tn-T, and SAPS II in combinations and alone, for predicting mortality in patients admitted to the ICU for respiratory disease.

\section{Methods}

This study was approved by our local ethics committee. The data were obtained from our hospital's electronic clinical and laboratory records system.

\section{Patients}

We retrospectively analyzed the medical records of 216 consecutive patients admitted to the ICU between December 2007 and December 2009 and whose CRP and troponin levels had been measured. Patients with chest pain and/or suspicion of acute coronary syndrome had been evaluated by a cardiologist. We excluded patients with acute coronary syndrome or pulmonary embolism. Neither CRP nor cTn-T had been used to guide diagnosis, management, or monitoring.

We recorded age, sex, history of hypertension, COPD, coronary artery disease, or renal failure, laboratory data (eg, hemoglobin, leukocyte, platelet count, and arterial blood gases), maximum CRP and cTn-T values at admission; cause of ICU admission, discharge diagnoses, requirement for invasive ventilation or noninvasive ventilation during and after hospitalization; Simplified Acute Physiology Score II (SAPS II) within 24 hours of ICU admission; ${ }^{16}$ and, for patients diagnosed with pneumonia, CURB-65 (confusion, urea nitrogen, respiratory rate, blood pressure, $\geq 65$ years of age) score. We included patients who developed acute respiratory distress syndrome according to American-European Consensus Committee criteria. ${ }^{17}$

\section{Blood Analysis}

Venous and arterial blood samples were collected and analyzed on admission. cTn-T was measured via electrochemiluminescence assay (Elecsys 2010, Roche, Mannheim, Germany). The normal cTn-T value is $<0.01 \mathrm{ng} /$ $\mathrm{mL}$. Serum CRP was measured nephelometrically (Date Behring BN II, Siemens Healthcare Diagnostics, Deerfield, Illinois) The normal CRP value is $<0.5 \mathrm{mg} / \mathrm{dL}$.

\section{Statistical Analysis}

Results are given as number and percent, mean $\pm \mathrm{SD}$, or median and range, as appropriate. We compared means with the Student $t$ test or the Mann-Whitney test. We used receiver operating curve (ROC) analysis to determine cutoff values for predicting mortality with cTn-T, CRP, and SAPS II. We compared discrete variables with the Fisher exact test (chi-square test). We used univariate regression to analyze mortality risk factors, and multivariate regression with a stepwise descending method for risk factors that had a $P<.10$ in the univariate analysis. We report the multivariable regression results as odds ratio and 95\% CI. $P<.05$ was considered statistically significant. Data analysis was with statistics software (SPSS 13.01, SPSS, Chicago, Illinois).

\section{Results}

We screened the medical records of 216 patients admitted to our ICU from the emergency department. We excluded 42 patients with pulmonary embolism and 16 patients with incomplete data, and thus analyzed the records of 158 patients (Table 1). The cohort's mean age was $67.1 \pm 13.6$ years, and $99(63 \%)$ were male. The most common reasons for ICU admission were pneumonia (65 patients), COPD exacerbation (39 patients), and hypercapnic respiratory failure (uncommon type 2 respiratory insufficiency, 18 patients) (Table 2). Comorbid conditions included diabetes mellitus in 29 patients (18\%), hypertension in 108 patients (68\%), and coronary artery disease in 71 patients (45\%). Hepatic dysfunction (aspartate transferase and/or alanine transferase substantially above normal $[<40 \mathrm{mg} / \mathrm{dL}]$ ) was present in 50 patients $(32 \%)$. Invasive ventilation was administered to 76 patients (48\%), and noninvasive ventilation to 27 patients $(17 \%)$. Mean ICU stay was 9.9 days (range 1-65 d), and mean total hospital stay was 14.1 days (range 1-72 d). 


\section{C-Reactive Protein and Troponin T for Risk Stratification of Intensive Care Patients}

Table 1. Subjects

\begin{tabular}{|c|c|c|c|c|}
\hline & $\begin{array}{c}\text { Total } \\
(n=158)\end{array}$ & $\begin{array}{l}\text { Survivors } \\
(n=80)\end{array}$ & $\begin{array}{l}\text { Non-Survivors } \\
\quad(n=78)\end{array}$ & $P$ \\
\hline Age $(y)$ & $67.1 \pm 13.6$ & $66.2 \pm 14$ & $67.9 \pm 13.3$ & .39 \\
\hline Male/female, no. (\%) & $99 / 59(63 / 37)$ & $50 / 30(62 / 38)$ & $49 / 29(63 / 37)$ & .85 \\
\hline ICU stay $(\mathrm{d})$ & $9.9 \pm 11.2$ & $9.2 \pm 10.8$ & $10.6 \pm 11.7$ & .82 \\
\hline Hospital stay (d) & $14.1 \pm 12.0$ & $16.9 \pm 12$ & $11.4 \pm 12.2$ & $<.001$ \\
\hline Invasive ventilation, no. (\%) & $76(48)$ & $25(33)$ & $51(67)$ & $<.001$ \\
\hline Noninvasive ventilation, no. (\%) & $27(17)$ & $7(26)$ & $20(74)$ & .006 \\
\hline $\mathrm{P}_{\mathrm{aO}_{2}}(\mathrm{~mm} \mathrm{Hg})$ & $66 \pm 25$ & $72 \pm 24$ & $60 \pm 25$ & $<.001$ \\
\hline $\mathrm{P}_{\mathrm{aCO}_{2}}(\mathrm{~mm} \mathrm{Hg})$ & $52 \pm 20$ & $49 \pm 18$ & $55 \pm 22$ & .07 \\
\hline Troponin $\mathrm{T}$ (ng/mL) & $0.09 \pm 0.30$ & $0.05 \pm 0.25$ & $0.14 \pm 0.33$ & $<.001$ \\
\hline C-reactive protein $(\mathrm{mg} / \mathrm{dL})$ & $12.8 \pm 12.3$ & $8.8 \pm 8.3$ & $17.0 \pm 14.0$ & $<.001$ \\
\hline Hepatic dysfunction, no. $(\%)^{*}$ & $50(32)$ & $26(33)$ & $24(31)$ & .80 \\
\hline Leukocyte count (cells $\times 10^{3}$ ) & $13.4 \pm 6.0$ & $13.6 \pm 5.9$ & $13.4 \pm 6.2$ & .86 \\
\hline Hemoglobin (g/dL) & $13.4 \pm 7.5$ & $13 \pm 2.2$ & $13.6 \pm 10.5$ & .08 \\
\hline Platelet count (cells $\times 10^{3}$ ) & $247 \pm 105$ & $250 \pm 113$ & $243 \pm 98$ & .99 \\
\hline Troponin $\mathrm{T} \geq 0.01 \mathrm{ng} / \mathrm{mL}$, no. (\%) & $96(61)$ & $35(37)$ & $61(63)$ & $<.001$ \\
\hline C-reactive protein $\geq 10 \mathrm{mg} / \mathrm{dL}$, no. (\%) & $75(48)$ & $24(32)$ & $51(68)$ & $<.001$ \\
\hline SAPS II & $36.3 \pm 10.5$ & $32.5 \pm 8.7$ & $40.1 \pm 10.9$ & $<.001$ \\
\hline \multicolumn{5}{|c|}{$\begin{array}{l}\text { values are mean } \pm \text { SD. } \\
* \text { Hepatic dysfunction means elevated aspartate transferase and/or alanine transferase. } \\
\text { ICU }=\text { intensive care unit } \\
\text { SAPS = Simplified Acute Physiology Score }\end{array}$} \\
\hline
\end{tabular}

Table 2. Admission Diagnoses $(n=158) *$

\begin{tabular}{lc}
\hline \hline & No. (\%) \\
\hline Acute respiratory distress syndrome & $8(5)$ \\
Infection & $75(47)$ \\
$\quad$ Sepsis & $40(53)$ \\
$\quad$ Pneumonia & $25(33)$ \\
$\quad$ Other infection & $10(14)$ \\
Interstitial lung disease & $8(5)$ \\
Cor pulmonale & $6(4)$ \\
Hypercapnic respiratory failure & $18(11)$ \\
COPD & $39(25)$ \\
Obesity-hypoventilation syndrome & $5(3)$ \\
Uncommon cause & $9(6)$
\end{tabular}

* Ten patients had more than one diagnosis.

Of the 65 patients admitted to the ICU with a diagnosis of pneumonia, $51(78 \%)$ had a CURB-65 score $\geq 3$ (Table 3). Sepsis was present in 40 of the patients with pneumonia. Other system infections were present in 10 patients. There was no significant difference in mortality between the patients with and without sepsis $(P=.37)$.

Fig. 1 shows the ROC curves for CRP, cTn-T, and SAPS II. Table 4 shows the sensitivity, specificity, and predictive values of cTn-T, CRP, and SAPS II for mortality.

Median CRP concentration at admission was $9.0 \mathrm{mg} / \mathrm{dL}$ (range $0.12-62.4 \mathrm{mg} / \mathrm{dL}$ ). CRP was normal in 8 patients
Table 3. Distribution of CURB-65 Scores

\begin{tabular}{lc}
\hline \hline CURB-5 Score & No. $(\%)$ \\
\hline 1 & $5(8)$ \\
2 & $9(14)$ \\
3 & $28(43)$ \\
4 & $17(26)$ \\
5 & $6(9)$ \\
\hline CURB-65 = index of confusion, urea nitrogen, respiratory rate, blood pressure, $\geq 65$ years of \\
age.
\end{tabular}

(5\%) and elevated in the remaining 150 patients (95\%). ROC analysis found a CRP cutoff value of $\geq 10 \mathrm{mg} / \mathrm{dL}$. The CRP area under the curve for mortality was 0.691 (95\% CI $0.608-0.775, P<.001)$, and the sensitivity and specificity for mortality were $65 \%$ and $70 \%$, respectively.

Median cTn-T concentration at admission was $0.015 \mathrm{ng} / \mathrm{mL}$ (range $0.01-2.1 \mathrm{ng} / \mathrm{mL}$ ). cTn-T was normal in 62 patients (39\%) and elevated in the remaining 96 patients $(61 \%)$. ROC analysis found a cTn-T cutoff value of $\geq 0.01 \mathrm{ng} / \mathrm{mL}$. The cTn-T area under the curve for mortality was 0.733 (95\% CI $0.655-0.812, P<.001)$, and the sensitivity and specificity for mortality were $78 \%$ and $56 \%$, respectively.

The mean SAPS II was $36.3 \pm 10.5$. ROC analysis found a SAPS II cutoff value of 35 . The SAPS II area under the curve was 0.707 (95\% CI $0.626-0.788, P<.001$ ), 


\section{C-Reactive Protein and Troponin T for Risk Stratification of Intensive Care Patients}

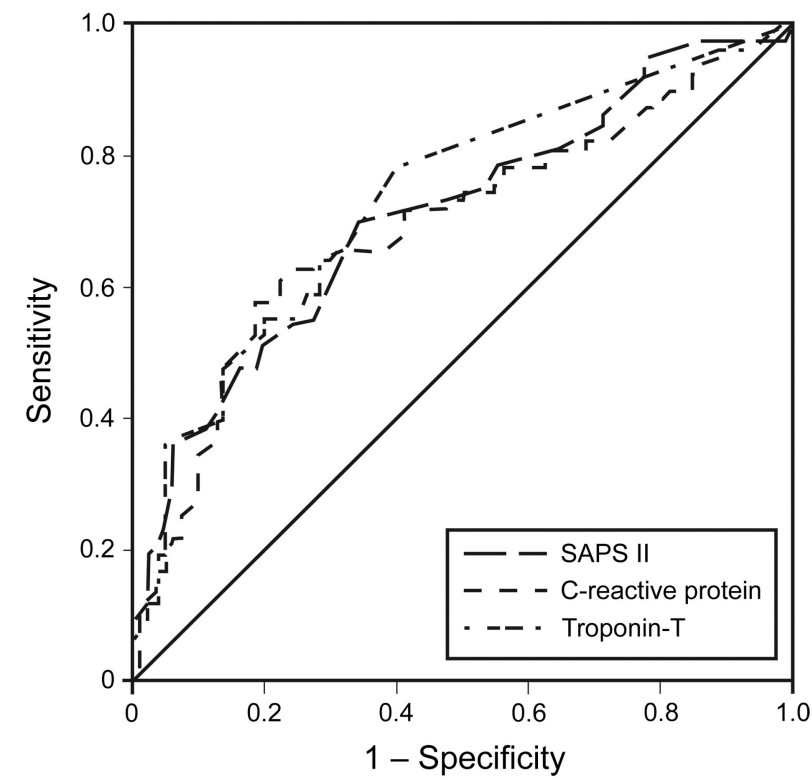

Fig. 1. Receiver operating characteristic curves showing the association between at-admission troponin T, C-reactive protein, and Simplified Acute Physiology Score II (SAPS II) and ICU survival.

and the specificity and sensitivity were 66 and 69, respectively.

Seventy-eight patients (48\%) died: 31 (40\%) from pneumonia or sepsis, $8(10 \%)$ from uncommon type 2 respiratory failure, $17(22 \%)$ from COPD, $6(8 \%)$ from acute respiratory distress syndrome, $4(5 \%)$ from cor pulmonale, and $12(15 \%)$ from unusual causes. There was no significant age difference between the patients discharged and those who died $(P=.32)$. Hospital stay was shorter in the patients who died $(7.0 \mathrm{~d}$ vs $14.0 \mathrm{~d}, P<.001)$. ICU stay was longer in the non-survivors than in the survivors $(7.0 \mathrm{~d}$ vs $6.0 \mathrm{~d}, P=.75$ ), but the difference did not reach statistical significance. Troponin level among patients with cardiac disease such as coronary artery disease or cardiac failure was not significant $(P=.16)$. Mortality in patients who received invasive ventilation was $67 \%$. Mortality was $29 \%$ in those with a normal troponin level (18 patients) and $63 \%$ in those with high troponin (60 patients) $(P<.001)$. CRP was $\geq 10 \mathrm{mg} / \mathrm{dL}$ in $65 \%$ (51 patients) of the subjects who died, and $<10 \mathrm{mg} / \mathrm{dL}$ in $32 \%$ (27 patients) of those who died $(P<.001)$. Hemoglobin, leukocyte, and platelet count were the same in the patients who survived and those who died. Median CRP in the nonsurvivors was $14.0 \mathrm{mg} / \mathrm{dL}$ (range $0.3-62.4 \mathrm{mg} / \mathrm{dL}$ ) and $5.9 \mathrm{mg} / \mathrm{dL}$ (range $0.1-41.2 \mathrm{mg} / \mathrm{dL}$ ) in those who survived $(P<.001)$. The mean SAPS II was $40.1 \pm 10.9$ in the non-survivors, and $32.5 \pm 8.7$ in the survivors $(P<.001)$. There was no significant correlation between disease type and mortality.
Because the SAPS II scoring system incorporates age, vasopressor use, mechanical ventilation, leukocyte count, and serum creatinine, these variables were not incorporated as separate variables in the univariate analysis. Stepwise univariate logistic regression analysis found that independent predictors of ICU mortality were cTn$\mathrm{T} \geq 0.01 \mathrm{ng} / \mathrm{mL}(P<.001), \mathrm{CRP} \geq 10 \mathrm{mg} / \mathrm{dL}(P<.001)$, SAPS II $>35(P<.001)$, and longer hospital stay $(P=.007)$. Variables that were not independent predictors of ICU mortality were history of hypertension or coronary artery disease, lower hemoglobin level, male sex, longer ICU stay, or CRP combined with cardiac cTn-T or SAPS II.

To investigate whether the combination CRP with cTn-T or SAPS II has any advantage over the aforementioned strategy for predicting ICU mortality, we analyzed 6 patient groups:

- $\mathrm{CRP} \geq 10 \mathrm{mg} / \mathrm{dL}$ alone

- $\mathrm{cTn}-\mathrm{T} \geq 0.01 \mathrm{ng} / \mathrm{mL}$ alone

- SAPS II > 35 alone

- $\mathrm{CRP} \geq 10 \mathrm{mg} / \mathrm{dL}$ combined with $\mathrm{cTn}-\mathrm{T} \geq 0.01 \mathrm{ng} / \mathrm{mL}$

- $\mathrm{CRP} \geq 10 \mathrm{mg} / \mathrm{dL}$ combined with SAPS II $>35$

- SAPS II $>35$ combined with cTn-T $\geq 0.01$

None of those variables/combinations had an advantage in predicting mortality in multivariate analysis, whereas multivariable regression analysis found that CRP $\geq 10 \mathrm{mg} / \mathrm{dL}$ was associated with 6.6-fold higher ICU mortality (95\% CI 1.7-21.3, $P=.005$ ) (Table 5).

\section{Discussion}

To our knowledge, CRP, troponin, and SAPS II, combined or alone, have not previously been investigated for predicting mortality in a group of ICU patients with respiratory disease. Our results indicate that CRP concentration alone is more useful than any combination of CRP, troponin, or SAPS II for predicting mortality in medical ICU patients.

Serum CRP is an acute-phase protein synthesized by the liver following stimulation by various cytokines, including tumor necrosis factor and interleukin-6. CRP rises substantially within hours of infection or inflammation, ${ }^{18}$ so critically ill patients often have elevated CRP at ICU admission. In our study, $48 \%$ of the patients had CRP $\geq 10 \mathrm{mg} /$ $\mathrm{dL}$, which was associated with a 6.6 -fold higher risk of death from any cause. Lobo et al reported that CRP $>10 \mathrm{mg} / \mathrm{dL}$ was associated with a 1.7-fold higher risk of ICU mortality than CRP $<1 \mathrm{mg} / \mathrm{dL}$, and that CRP rose further in respiratory diseases than in renal, cardiovascular, or neurological diseases. ${ }^{19}$ Prieto et al found that CRP $>10 \mathrm{mg} / \mathrm{dL}$ (in $33 \%$ of their patients) was associated with a 2.3 -fold higher 


\section{C-Reactive Protein and Troponin T for Risk Stratification of Intensive Care Patients}

Table 4. Sensitivity, Specificity, and Predictive Values of Cardiac Troponin T, C-Reactive Protein, and SAPS II for Mortality*

\begin{tabular}{|c|c|c|c|c|}
\hline & Sensitivity & Specificity & $\begin{array}{c}\text { Negative Predictive } \\
\text { Value }\end{array}$ & $\begin{array}{c}\text { Positive Predictive } \\
\text { Value }\end{array}$ \\
\hline Cardiac troponin $\mathrm{T} \geq 0.01 \mathrm{ng} / \mathrm{mL}$ & $78(67-86)$ & $56(45-67)$ & $73(60-83)$ & $64(53-73)$ \\
\hline C-reactive protein $\geq 10 \mathrm{mg} / \mathrm{dL}$ & $65(54-76)$ & $70(59-79)$ & $67(56-77)$ & $68(56-78)$ \\
\hline SAPS II > 35 & $69(57-78)$ & $66(54-76)$ & $69(57-79)$ & $67(55-77)$ \\
\hline $\begin{array}{l}\text { * All values are percent and } 95 \% \text { CI. } \\
\text { SAPS = Simplified Acute Physiology Score }\end{array}$ & & & & \\
\hline
\end{tabular}

Table 5. Multivariable Regression Analysis for Overall Mortality

\begin{tabular}{lcll}
\hline \hline & $\begin{array}{l}\text { Odds } \\
\text { Ratio }\end{array}$ & $95 \%$ CI & $P$ \\
\hline C-reactive protein $\geq 10 \mathrm{mg} / \mathrm{dL}$ & 6.6 & $1.7-21.3$ & .005 \\
SAPS II $>35$ & 3.4 & $0.9-13.2$ & .07 \\
Cardiac troponin T $\geq 0.01 \mathrm{ng} / \mathrm{dL}$ & 2.3 & $0.6-9.8$ & .24 \\
C-reactive protein $\geq 10 \mathrm{mg} / \mathrm{dL}$ and & 1.1 & $0.2-5.4$ & .92 \\
$\quad$ cardiac troponin T $\geq 0.01 \mathrm{ng} / \mathrm{dL}$ & & & \\
C-reactive protein $\geq 10 \mathrm{mg} / \mathrm{dL}$ & 0.6 & $0.1-2.9$ & .52 \\
$\quad$ and SAPS II $>35$ & & & \\
Cardiac troponin T $\geq 0.01 \mathrm{ng} / \mathrm{dL}$ & 1.3 & $0.3-5.4$ & .70
\end{tabular}
and SAPS II $>35$

SAPS $=$ Simplified Acute Physiology Score

ICU mortality. ${ }^{20}$ Therefore, a CRP $>10 \mathrm{mg} / \mathrm{dL}$ is of critical importance on ICU admission.

Serum cTn-T was elevated in $61 \%$ of our patients. Myocardial injury is common in ICU patients, and troponin is elevated in $12-85 \%$ of ICU patients without acute coronary syndrome. ${ }^{21}$ Troponin level is reportedly higher in patients with sepsis and hypotension: $85 \%$ and $74 \%$, respectively. ${ }^{5,22}$ In our study the highest troponin levels were in the patients with cor pulmonale and COPD: 67\% and $66 \%$, respectively. In another study, elevated cardiac troponin was found in $70 \%$ of patients with COPD exacerbation. ${ }^{23}$ As expected, high troponin level in patients with COPD and cor pulmonale is correlated with myocardial damage caused by elevated pressure in the right ventricle secondary to hypoxia. In the present study, elevated cTn-T was associated with 4.6-fold higher overall mortality on univariate analysis. A meta-analysis found that elevated troponin was associated with a 2.5 -fold higher risk of ICU mortality. ${ }^{21}$

Our multivariate analysis found that CRP $\geq 10 \mathrm{mg} / \mathrm{dL}$, considered alone, was associated with a 6.6-fold higher ICU mortality. Interestingly, combining CRP with cTn-T or SAPS II made no contribution to predicting mortality. Although the combination of CRP and Tn-T was a mortality predictor in univariate analysis, it was not significant in the multivariate analysis. cTn-T and CRP are released via different pathways, have different half-lives, and CRP induced by a stimulus rises faster than cTn-T. Therefore, a normal admission troponin level could cause a false negative assessment of ICU mortality risk. Combination biomarkers strategies for risk prediction is an emerging field, particularly for pulmonary embolism and cardiovascular diseases, but this may not be true for ICU patients because of their complexity and heterogeneity.

The prognostic role of CRP in cardiovascular diseases in particular has been well described. High CRP is an independent risk factor for hospital readmission and mortality in patients with cardiac failure, development of atrial fibrillation, and thromboembolism. ${ }^{24}$ CRP can be used in deciding on early or late ICU discharge and in monitoring response to treatment. A rising $\mathrm{CRP}$ in an ICU patient may also indicate nosocomial infection. In a large hospitalbased study of the relationship of CRP and mortality, Marsik et al suggested CRP as a factor in triage. ${ }^{25}$ CRP can also be a criterion in selecting the treatment for underlying disease, and prospective studies are needed. Moreover, CRP can be used very quickly, is economical, and the results can easily be interpreted and compared to cTn-T and other complex biomarkers. The SAPS and APACHE scores commonly used in ICU prognosis are complex, involve several variables, and are difficult to interpret.

In contrast to the literature, mortality was quite high in our study. In several studies, mortality in diseases stemming from the respiratory system was compared to that from other systems. Our study included only respiratory patients, and the need for invasive ventilation was quite high, at $48 \%$. In a study with 108 patients, Wu et al administered invasive ventilation to $53 \%$ of the patients, and total mortality was 39\%.7 In a study by Minkin et al, $62 \%$ of patients required mechanical ventilation, and total mortality was 39\%. ${ }^{26}$ In another study, total mortality was $20 \%$, and $34 \%$ in pulmonary diseases. ${ }^{13}$ King et al had a total mortality of $19 \%$, and $33 \%$ in pulmonary diseases. ${ }^{8}$ In addition, in our study, patients with severe pneumonia made up $40 \%$ of the non-survivors, and $78 \%$ of the pneumonia patients had a CURB-65 score $\geq 3$. Mortality was $48 \%$ in patients admitted to the ICU with a diagnosis of pneumonia. The literature has reported mortality of 15$57 \%$ in patients with a CURB-65 score $\geq 3 .{ }^{27}$ A multi- 


\section{C-Reactive Protein and Troponin T for Risk Stratification of Intensive Care Patients}

center study with 1,426 respiratory disease patients admitted to the respiratory ICU had a mortality of $44 \% .{ }^{28}$ The main reason for the high mortality in our ICU patients may have been those patients, because ours is a tertiary-care hospital, where patients are admitted for severe illness. The low number of beds in our ICU might also have increased the mortality, because less seriously ill patients were not admitted to the ICU.

\section{Limitations}

This was a retrospective study, though the fact that all patient data, epicrisis, and daily progress were available is important to the study's reliability. Further prospective randomized clinical trials are needed to evaluate the use of biomarkers for determining who should be admitted to the ICU from the emergency department.

Second, we did not ascertain the post-discharge longterm outcomes of the survivors. Previous studies found a correlation between elevated CRP and troponin and postICU-discharge mortality. ${ }^{13,24,29}$ Grander et al determined that every unit of CRP increase raised post-discharge mortality 1.46 -fold. ${ }^{13}$ Ho et al found a post-ICU mortality of $4 \%$ in patients with a CRP of $9 \mathrm{mg} / \mathrm{dL}$, and $22 \%$ in patients with a CRP of $30 \mathrm{mg} / \mathrm{dL} .{ }^{24}$

Third, troponin levels were not subsequently measured in patients with initial normal troponin and included in the study. This is potentially important, because troponin can rise 6-12 hours after hospital admission. ${ }^{30}$

\section{Conclusions}

As in previous studies, this study showed that elevated CRP at prognostic scanning of medical ICU patients was an independent mortality risk factor. In addition, CRP is an easily applicable, simple biomarker and can be used for risk stratification of ICU patients.

\section{REFERENCES}

1. Morrow DA, Cannon CP, Rifai N, Frey MJ, Vicari R, Lakkis N, et al. Ability of minor elevations of troponins I and $\mathrm{T}$ to predict benefit from an early invasive strategy in patients with unstable angina and non-ST elevation myocardial infarction: results from a randomized trial. JAMA 2001;286(19):2405-2412.

2. Antman EM, Tanasijevic MJ, Thompson B, Schactman M, McCabe $\mathrm{CH}$, Cannon $\mathrm{CP}$, et al. Cardiac-specific troponin I levels to predict the risk of mortality in patients with acute coronary syndromes. N Engl J Med 1996;335(18):1342-1349.

3. Roongsritong C, Warraich I, Bradley C. Common causes of troponin elevations in the absence of acute myocardial infarction: incidence and clinical significance. Chest 2004;125(2):1877-1884.

4. Lazzeri C, Bonizzoli M, Cianchi G, Gensini GF, Peris A. Troponin I in the intensive care unit setting: from the heart to the heart. Intern Emerg Med 2008;3(1):9-16.
5. Ammann P, Fehr T, Minder EI, Günter C, Bertel O. Elevation of troponin I in sepsis and septic shock. Intensive Care Med 2001; 27(6):965-969.

6. Stein R, Gupta B, Agarwal S, Golub J, Bhutani D, Rosman A, Eng C. Prognostic implications of normal $(<0.10 \mathrm{ng} / \mathrm{mL})$ and borderline ( 0.10 to $1.49 \mathrm{ng} / \mathrm{mL}$ ) troponin elevation levels in critically ill patients without acute coronary syndrome. Am J Cardiol 2008;102:509-512.

7. Wu TT, Yuan A, Chen CY, Chen WJ, Luh KT, Kuo SH, et al. Cardiac troponin i levels are a risk factor for mortality and have an additive effect to the APACHE II score in outcome prediction. Shock 2004;22(2):95-101.

8. King DA, Codish S, Novack V, Barski L, Almog Y. The role of cardiac troponin I as a prognostic factor in critically ill medical patients: a prospective observational cohort study. Crit Care 2005; 9(4):390-395.

9. Okamura JM, Miyagi JM, Terada K, Hokama Y. Potential clinical applications of C-reactive protein. J Clin Lab Anal 1990;4(3):431-235.

10. Musunuru K, Kral BG, Blumenthal RS, Fuster V, Campbell CY, Gluckman TJ, et al. The use of high-sensitivity assays for C-reactive protein in clinical practice. Nat Clin Pract Cardiovasc Med 2008; 5(10):621-635.

11. Abou-Raya S, Abou-Raya A, Naim A, Abuelkheir H. Chronic inflammatory autoimmune disorders and atherosclerosis. Ann N Y Acad Sci 2007;1107:56-67.

12. Forrester JS, Libby P. The inflammation hypothesis and its potential relevance to statin therapy. Am J Cardiol 2007;99(5):732-738.

13. Grander W, Dünser M, Stollenwerk B, Siebert U, Dengg C, Koller B, et al. CRP Levels and Post-Intensive Care Unit Mortality in Non-Surgical Intensive Care Patients. Chest 2010;138(4):856-862.

14. Ozsu S, Karaman K, Mentese A, Ozsu A, Karahan SC, Durmus I, et al. Combined risk stratification with computerized tomography/ echocardiography and biomarkers in patients with normotensive pulmonary embolism. Thromb Res 2010;126(6):486-492.

15. Jenny NS, Yanez ND, Psaty BM, Kuller LH, Hirsch CH, Tracy RP. Inflammation biomarkers and near-term death in older men. Am J Epidemiol 2007;165(6):684-695.

16. Le Gall JR, Lemeshow S, Saulnier F. A new Simplified Acute Physiology Score (SAPS II) based on a European/North American multicenter study. JAMA 1993;270(24):2957-2963.

17. Bernard GR, Artigas A, Brigham KL, Carlet J, Falke K, Hudson L, et al. The American-European Consensus Conference on ARDS: definitions, mechanism, relevant outcomes, and clinical trial coordination. Am J Respir Crit Care Med 1994;149(3):818-824.

18. Thijs LG, Hack CE. Time course of cytokine levels in sepsis. Intensive Care Med 1995;21(Suppl 2):258-263.

19. Lobo SM, Lobo FR, Bota DP, Lopes-Ferreira F, Soliman HM, Mélot C, Vincent JL. C-reactive protein levels correlate with mortality and organ failure in critically ill patients. Chest 2003;123(6):2043-2049.

20. Prieto MF, Kilstein J, Bagilet D, Pezzotto SM. Reactive protein as a marker of mortality in intensive care unit. Med Intensiva 2008;32(9): 424-430.

21. Lim W, Qushmaq I, Devereaux PJ, Heels-Ansdell D, Lauzier F, Ismaila AS, et al. Elevated cardiac troponin measurements in critically ill patients. Arc Intern Med 2006;166(22):2446-2454.

22. Arlati S, Brenna S, Prencipe L, Marocchi A, Casella GP, Lanzani M, Gandini C. Myocardial necrosis in ICU patients with acute noncardiac disease: a prospective study. Intensive Care Med 2000;26(1): 31-37.

23. Martins CS, Rodrigues MJ, Miranda VP, Nunes JP. Prognostic value of cardiac troponin I in patients with COPD acute exacerbation. Neth J Med 2009;67(10):341-349.

24. Ho KM, Lee KY, Dobb GJ, Webb SA. C-reactive protein concentration as a predictor of inhospital mortality after ICU discharge: a prospective cohort study. Intensive Care Med 2008;34(3):481-487. 


\section{C-Reactive Protein and Troponin T for Risk Stratification of Intensive Care Patients}

25. Marsik C, Kazemi-Shirazi L, Schickbauer T, Winkler S, Joukhadar C, Wagner OF, Endler G. C-reactive protein and all-cause mortality in a large hospital-based cohort. Clin Chem 2008;54(2):343-349.

26. Minkin R, Cotiga D, Noack S, Dobrescu A, Homel P, Shapiro JM. Use of admission troponin in critically ill medical patients. J Intensive Care Med 2005;20(6):334-338.

27. Mandell LA, Wunderink RG, Anzueto A, Bartlett JG, Campbell GD, Dean NC, et al. Infectious Diseases Society of America/American Thoracic Society consensus guidelines on the management of community acquired pneumonia in adults. Clin Infect Dis 2007;44(Suppl 2):27-72.
28. Vasilyev S, Schaap RN, Mortensen JD. Hospital survival rates of patients with acute respiratory failure in modern respiratory intensive care units: an international, multicenter, prospective survey. Chest 1995;107(4): 1083-1088

29. Babuin L, Vasile VC, Rio Perez JA, Alegria JR, Chai HS, Afessa B, Jaffe AS. Elevated cardiac troponin is an independent risk factor for short-and long-term mortality in medical intensive care unit patients. Crit Care Med 2008;36(3):759-765.

30. Kucher N, Printzen G, Goldhaber SZ. Prognostic role of brain natriuretic peptide in acute pulmonary embolism. Circulation 2003; 107(20):2545-2547. 